\title{
Human cloning and headless frogs
}

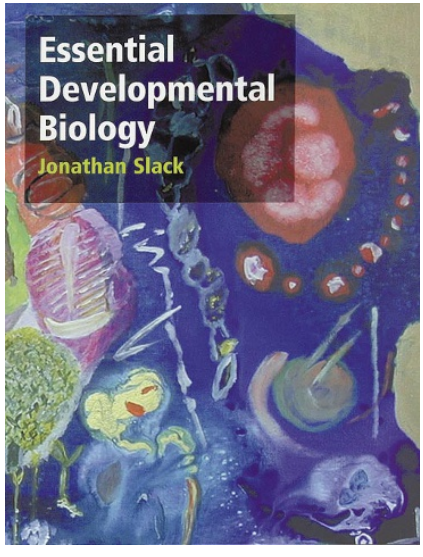

\author{
Essential Developmental Biology \\ by Jonathan Slack \\ Blackwell Science · December 2000 \\ Paperback $116.50 / \$ 37.95$
}

Randall T. Moon

A ny paperback book purporting to enlighten readers on human cloning, four-legged chickens and headless frogs has my full attention. Jonathan Slack's intended target audience, undergraduate students enrolled in classes in developmental biology who have little prior knowledge of the subject, will also find much deserving of their attention. For those unfamiliar with this century-old discipline, developmental biology has been growing immensely over the past decade, owing to its interdisciplinary nature and its synthesis of genetics, biochemistry, cell biology, anatomy, embryology and molecular biology. As a discipline that is well poised to address many post-genomic questions, undergraduate and graduate classes in this subject have been in demand. However, students are often confronted with a rather complex subject that generally presupposes considerable prior knowledge in many disciplines, and the current textbooks are often immense. What, then, should an instructor have students read?

Jonathan Slack is a highly regarded practising developmental biologist who has a firm grasp of the subject-perhaps a tribute to the demanding questions of his students, although more probably a reflection of his organized and scholarly mind. He has largely done a wonderful job of filling a useful niche, by providing an up-to-date portable book that distils the broad discipline of animal developmental biology into something that can be dealt with in the duration of a typical undergraduate class.

My favourite aspects of the book are those least devoted to specific facts, especially when the author waxes philosophical about the subject, and how researchers pursue it. The first chapter, on the excitement of developmental biology, covers the present and future impact on society of this discipline. The successes of the discipline in identifying new targets for drug therapies, in understanding signal transduction pathways and in shedding light on regeneration and organ development as possible therapies, and its contributions to prenatal screening, are all mentioned. I suspect that students would like to hear more about this, leavened with specific examples, before they immerse themselves in the hard facts.

In addition, the organization of the book makes considerable sense. Before students learn about any specific organism or process, there is a highly useful and readable Section 1 on the groundwork of the discipline. It opens with a chapter on the key molecular components, covering genes, signal transduction systems, and some cell biology. This is followed by succinct chapters on common features of development, developmental genetics, experimental embryology, and techniques for the study of development. These chapters give students some insights into the major advances and techniques in the discipline, and provide a general framework for understanding the development of specific organisms.

Section 2 of the book deals with major model organisms. In the past, many developmental biology textbooks have been organized by processes, so that chapters are arranged to cover fertilization, gastrulation, and so on. Unfortunately, animals are so diverse in how they undergo these processes that chapters have often become bogged down in explanations of the many differences between organisms. As a result, students generally could not sit down and describe the sequential steps in development of any one organism. Jonathan Slack is to be commended for dispensing with this strategy, dealing instead with various model organisms (Xenopus, zebrafish, chicken, mouse, fruitfly, Drosophila and the nematode Caenorhabditis elegans) one at a time. Thus, one can finally use a companion book to teach students how specific organisms develop, without the distraction of explaining all the permutations of each step in development. Graduate students, and others new to working with a given model organism, will also find this book a valuable overview and resource. For example, the chapter on the mouse nicely explains the analysis of chimaeras, embryonic stem cells, how gene knockouts are achieved experimentally, how conditional knockouts work, and what gene trapping and enhancer traps are good for.

The third section of the book covers the rapidly expanding areas of 'Organogenesis and Regeneration'. Although many other texts cover these subjects, this is one of the few to deal adequately with stem cells, giving examples of what they are and what they can become, and discussing the future promise of these cells.

No review would be complete without raising a few quibbles. First, although the book does a wonderful job of presenting principles of development, in the fervent pursuit of being concise the specific facts and key words (in bold) come at a fast and furious pace. This renders the book a wonderful companion to lectures (its stated goal), and much less suitable for those interested in becoming self-educated on the subject. Second, the book scrupulously avoids discussing individuals in this research area. Although this has the advantage of not seeming to play favourites, there are and have been many great personalities in the field. Finally, the 'further reading' sections at the end of each chapter would benefit from more current references. A notable omission is that although the book lists the proper website for most model organisms, both the excellent website for the zebrafish community and the NIH 'model organisms' website were overlooked. However, these are oversights that could easily be repaired in future editions, and they in no way detract from the utility of the book.

I imagine that writing a book of any type is not an easy task. Students and faculty interested in a concise companion book to an undergraduate class on developmental biology will be thankful that Jonathan Slack took the time to prepare this firstand, it is to be hoped, not last-edition. $\square$ Randall T. Moon is at the Howard Hughes Medical Institute, University of Washington, Seattle, Washington 98195, USA email:rtmoon@u.washington.edu 